\title{
Study on collaborative warning and disaster mitigation mode of non-engineering measures of reservoirs and mountain torrent disaster control
}

\author{
LI Hongen ${ }^{1, ~ a ~, ~ L I ~ Z h e n g ~}{ }^{1, b}$, XU Haifeng ${ }^{1, c}$, He Yongjun ${ }^{1,}$, ,FAN Guangya ${ }^{1, e}$ \\ ${ }^{1}$ Dam Safety Management Department, Nanjing Hydraulic Research Institute, Nanjing 210029, P. R. \\ China \\ aheli@nhri.cn, ${ }^{\mathrm{b}}$ lizheng@nhri.cn, ${ }^{\mathrm{C} h f x u @ n h r i . c n,}{ }^{\mathrm{d}} \mathrm{yjhe@nhri.cn,}{ }^{\mathrm{e}} \mathrm{gyfan} @$ nhri.cn
}

Keywords: mountain torrent disaster control, reservoir projects, non-engineering measures, collaborative warning, disaster mitigation mode

Abstract: The engineering measures and non-engineering measures are the two complementary supports of mountain torrent disaster control. Through a series of approaches such as danger control and reinforcement, regulation construction, management system reform in recent years, reservoirs as the traditional sense of engineering measures, already have considerable capabilities of non-engineering measures, its water regime, rainfall, engineering conditions monitoring technology are improved continually, monitoring and warning system are optimized gradually, risk management consciousness and operability of emergency plan are strengthened continuously. On the base of giving full play to non-engineering measures functions and advantages of reservoir, through the comparative analysis of the existing hydrological telemetric system, monitoring system of dam safety and non-engineering measures of mountain torrent disaster control, this paper tried to share and integrate important information of reservoir and key links of implementing non-engineering measures of mountain torrent disaster control, a collaborative warning and disaster mitigation mode of non-engineering measures of reservoirs and mountain torrent disaster control was put forward. The information sharing, joint management and collaborative prediction of reservoir projects and non-engineering measures of mountain torrent disaster control were realized, and a new idea was provided to solve complicated problems such as daily management of non-engineering measures of mountain torrent disaster control and the warning information collection of sudden mountain torrent disaster control event.

\section{Introduction}

In recent years, mountain torrent disaster present multiple, prone, frequent and recurrent features, Mountain torrent disaster caused by local extreme precipitation events occurred frequently, mountain torrents disaster death toll accounting for the proportion of deaths flood was a significant increasing trend. From year 1950 to 2000, 263 thousand people in China died due to floods, of which 180 thousand people died due to mountain torrents, accounting for $68.4 \%$ of total deaths, a high proportion of $84 \%$ in certain year. The proportion of heavy casualties caused by mountain torrent disaster in Zhouqu county, Gansu province in 2010, exceeded $90 \%$.

The engineering measures and non-engineering measures are the two complementary supports of mountain torrent disaster control ,the former mainly includes the dike river regulation, mountain torrent ditch and landslide governance, control of soil erosion and reservoir project defense, etc.The reservoir project in the mountain torrent disaster control of small watershed has played an important role in flood control security, 2058 mountain torrent disaster control counties have distribution in reservoir engineering, mainly small and medium-sized reservoirs, especially in earth-rock dam project.Our country attaches great importance to reservoir dam safety and management work, In recent years, through the reinforcement, and regulations, management reform and a series of ways, and gradually build the security system of the dam. After the State Council approved Nationwide strengthening and eliminating dangers for reservoirs special planning in 2008,6240 large and 
medium ,5400 key small (1) sized and 40.9 thousand key small (2) sized reservoirs were strengthened and eliminated dangers, which has improved the ability to promote the beneficial ,abolish the harmful and flood control security of reservoirs as engineering measures in the susceptible area of mountain torrent.Primary function in the traditional sense reservoir project is flood control security, and is a major project of mountain torrent disaster control measures. In all engineering measures of mountain torrent disaster control,the effect of reservoir project is most important because it is the most effective measures for improving the capability of mountain flood control of small watershed through optimization and reasonable scheduling of flood storage which can give full play to reservoir flood detention and peak cutting effect and reduce flood drainage pressure from downstream channel [1].

Study of mountain torrent disaster control mostly focused on the optimization and implement of non-engineering measures, but it is relatively infrequent that how to combine the non-engineering measures of the mountain torrent disaster control better with the non-engineering measures of reservoir engineering [2-4], thus playing a role of reservoir engineering for warning of water information of reservoir area and dam site engineering conditions as the non-engineering measures. This paper based on the analysis of mitigation function position of reservoir engineering in the susceptible area of mountain torrent, facing the aspects of non-engineering measures of mountain torrent disaster control which primarily includes monitoring system, warning platform and warning system, mass observation and mass preparedness, etc, and exploring the possibility of omnibearing combination between the reservoir engineering and the non-engineering measures of the mountain torrent disaster control in the aspects of information sharing and warning index optimization and emergency plan for unexpected events, that aims to further exploit the social and economical benefits of disaster prevention and mitigation of the non-engineering measures of the mountain torrent disaster control.

\section{Index optimization of mountain torrent disaster warning and critical rainfall index optimization}

Mountain torrent disaster forecast warning is an important part of the mountain torrent disaster prevention and control. As a core index of this, mountain torrent disaster critical rainfall index [5] is the important foundation of mountain torrent disaster forecast and early warning, which will directly affect the rate of non-response rates and false rate of forecast. According to the different definition of critical rainfall, at present there are two main types of calculation method[6]. One is statistical induction method using rainfall during a statistical characteristic value (critical rainfall) to distinguish whether a disaster happens or not, through the statistical analysis of accumulative rainfall and the corresponding relation of mountain flood disasters, the other is hydrology and hydraulics method judging whether a disaster happens or not through comparing the river water level or flow, and back stepping the critical rainfall surface according to the channel security water level and discharge.

In contrast with statistical induction method, the hydrologic hydraulic method on the basis of hydrological and hydraulics process formed by mountain flood disasters has simple principles, which has clear requirements on the data such as rainfall, underlying surface condition, runoff, channel characteristics etc.. This method has a more explicit theoretical basis, with higher accuracy and reliability of the critical rainfall index. It is an effective way to determine the critical rainfall of mountain torrent disaster warning and forecasting system of the core index accuracy and reliability using hydrologic and hydraulic method. For instance, hydrologic and hydraulic method has been widely used in flash flood guidance system (FFGS)[7] and HEC-DHM. In Mountain torrent disaster prevention and control of the project implementation plan (2013-2015), it has begun to pay more attention to the target watershed underlying surface characteristics on information collection, such as villages along the river channel control section measurement, etc., and lay the foundation of promoting the application of hydrologic and hydraulic method in critical rainfall calculation. 
In the process of consolidation or design in reservoir project in the target small watershed, there are strict requirements for flood control standard. The collection and analysis are usually made in detail of data such as historical flood of experiment of rainfall precipitation station, relevant hydrometric station and gauging station in the basin and the influence of human activities on the hydrological parameters, reservoir catchment area and outflow projects, water storage project and water diversion project within the area etc., in order to determine the design flood and flood regulating calculation, check flood prevention ability, etc. To meet the needs of the reservoir safety management, many reservoir project added precipitation station in the reservoir area during consolidating, so as to improve warehouse flood forecast accuracy. Reservoir project of existing hydrological data and rainfall regime monitoring facilities can be shared with mountain torrent disaster prevention warning system of non-engineering measures through the appropriate way using the local flood prevention platform. Therefore, when deriving the critical rainfall using the hydrologic and hydraulic method, attention should be paid to collecting, analyzing and organizing reservoir project data in the basin. The reservoir water rainfall regime monitoring data should be incorporated into small watershed rainfall regime information system in a timely manner, in order to use the rich water reservoir project rainfall regime data to fulfill the insufficient of no or less data in newly established precipitation stations and water flow stations for non-engineering measures of the mountain torrent disaster prevention and control.

\section{Emergency Response Mechanism Optimization of Mountain Torrent Disaster Control System}

Non-engineering measures of Mountain torrent disaster mainly include monitoring system, monitoring and warning platform, warning system, mass observation and mass preparedness and so on. At present the national and local main investment and energy focus on hardware and software construction such as monitoring equipment and warning system, while how to reduce the safety risk caused by mountain torrent disaster through operable emergency plan is just at the very beginning step. At the same time, as the concept of risk in the dam safety assessment and management unceasingly strengthens, the non-engineering measures such as reservoir dam safety management emergency contingency plans and reservoir emergency dispatch has gradually become the methodology and approach to Reduce and control the risk of dam in order to ensure dam safety and control the reservoir dam risk. Recently, Guidelines for Emergency Plan Preparation in Dam Safety Management(trial implementation) and Compilation guide of flood control operation plan have been published and carried out, reservoir dam safety management has gradually experienced the conversion from the traditional idea of "engineering safety management" to "project risk management".

In 2014 Ministry of Water Resources issued Guideline on the Compilation of Emergency Preparedness Plan for the Prevention of Flash Flood Disaster (SL666-2014), which generally stipulated the basic framework of emergency preparedness plan for the prevention of mountain torrent disaster. Currently in non-engineering measures at the county level, it is infrequent that the counties make effective emergency preparedness plan for the prevention of mountain torrent disaster according to the guideline. Compared with Guidelines for Emergency Plan Preparation in Dam Safety Management(trial implementation), there are a lot of common and similarities between the two guidelines, but it has brought a lot of difficulties to the local water conservancy in emergency preparation and practice owing to the lack of grading standards and warning level dividing standard of mountain torrent disaster.

So utilization of reservoir risk management experience in the susceptible area of mountain torrent is an effective approach to improve operability of emergency plan of the mountain torrent disaster prevention in the county. In particular, relevant content of emergency plan preparation in dam safety management should be fully considered in the process of mountain torrent disaster prevention plan 
compiling, for instance, through table 1 in Guidelines for Emergency Plan Preparation in Dam Safety Management (trial implementation) to definite the grading standards of mountain torrent disaster according to loss of life or social environment influence, and through table 2 to initially estimate warning level dividing standard, and then yield the maximum disaster mitigation benefit of non-engineering measures such as mountain torrent disaster control of monitoring and warning system.

TABLE 1: Grading Standards According to Loss of Life

\begin{tabular}{|c|c|c|c|c|}
\hline severity (level) & especially serious ( I ) & Magnitude ( II ) & Severe (III) & General (IV) \\
\hline loss of life L (people) & $\mathrm{L} \geq 50$ & $50>\mathrm{L} \geq 10$ & $10>\mathrm{L} \geq 3$ & $\mathrm{~L}<3$ \\
\hline
\end{tabular}

TABLE 2: Warning Level Dividing Standard

\begin{tabular}{|c|c|c|c|c|}
\hline severity (level) & especially serious ( I ) & magnitude ( II ) & Severe (III) & General (v) \\
\hline warning level & I & II & III & IV \\
\hline warning level identification & red & orange & yellow & blue \\
\hline
\end{tabular}

\section{Collaborative Warning and Disaster Mitigation Mode of Non-engineering Measures of Reservoirs and Mountain Torrent Disaster Control}

Through the foregoing comparative analysis of non-engineering measures of mountain torrent disaster control, the existing hydrological telemetric system and monitoring system of dam safety, a collaborative warning and disaster mitigation mode of safety monitoring system of reservoirs and mountain torrent disaster control was put forward(FIGRURE 1).

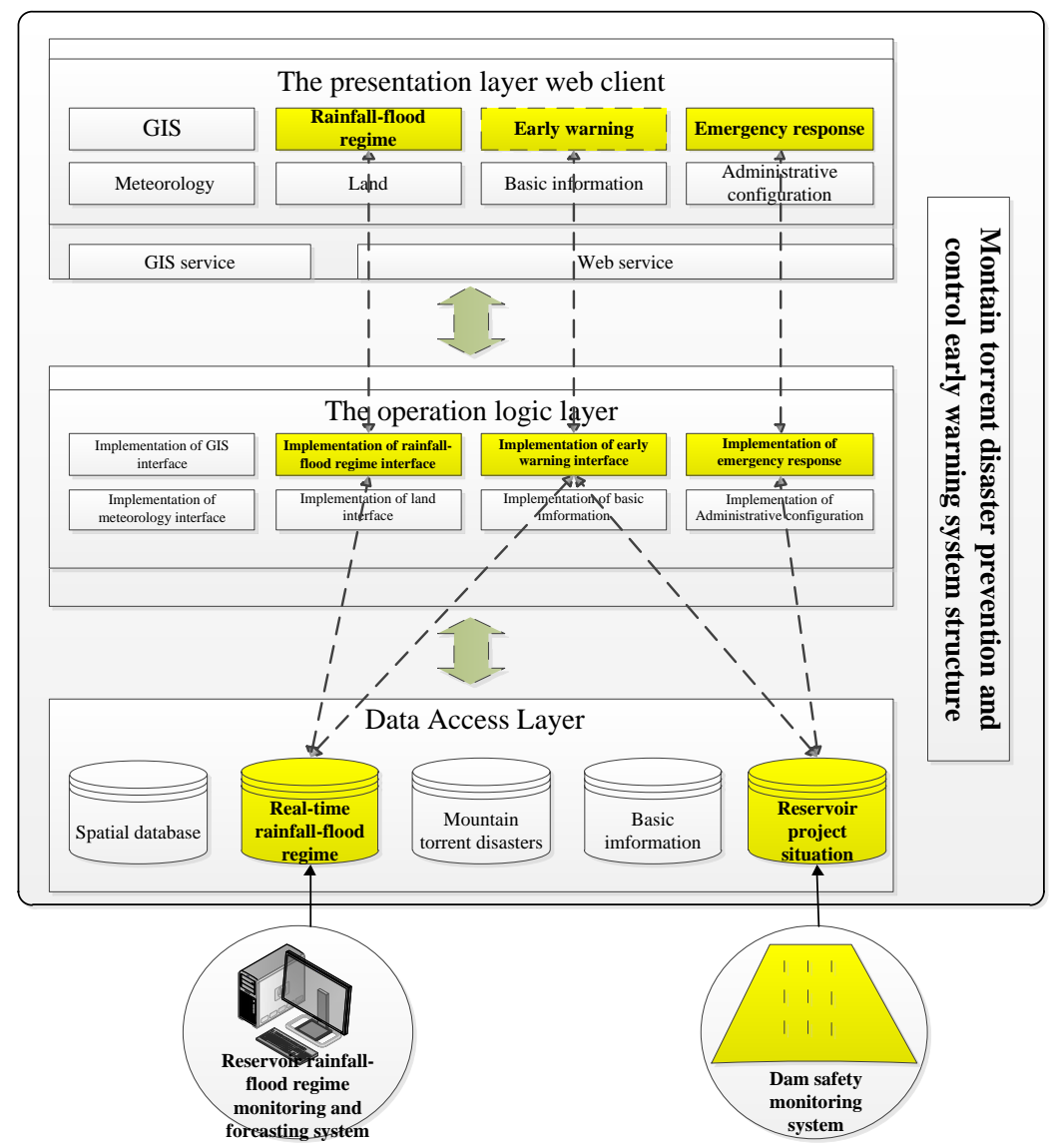

FIGURE 1 Collaborative Warning and Disaster Mitigation Mode of Non-engineering Measures of Reservoirs and Mountain Torrent Disaster Control 


\section{Conclusions}

(1) Calculating critical precipitation through hydrological hydraulic method is the inevitable tendency of mountain torrent disaster control implementation, that contains collection, analysis and arrangement of reservoir within the basin, bringing monitoring data of rainfall in reservoir area into rainfall information system in small watershed, taking advantage of rich rain and water information of reservoir to make up for the lack of new-built small watershed precipitation station data, thus improving the accuracy and reliability of critical precipitation calculated by hydrological hydraulic method.

(2) Safety monitoring system of reservoir can be used as important supplement of the non-engineering measures monitoring and warning platform of mountain torrent disaster control. Also, the monitoring system of reservoir safety should be accepted into monitoring platform of mountain torrent disaster control in an appropriate way, realizing comprehensive information sharing and integration between monitoring and warning system of mountain torrent disaster control and monitoring system of reservoir safety.

(3) Utilization of reservoir risk management experience in the susceptible area of mountain torrent is an effective approach to improve operability of emergency plan of the mountain torrent disaster prevention in the county. Based on the emergency plan of dam safety management, initially estimating grading standards and warning level dividing standard of mountain torrent disaster can effectively reduce problem and lower the difficult which the local water conservancy encounter in emergency preparation and practical operation.

(4) Through comparison between the non-engineering measures of mountain torrent disaster control and existing water rainfall regime telemetry system and dam safety monitoring system of reservoir project, a synergy warning mode for disaster reduction of reservoir project safety monitoring system and mountain torrent disaster prevention warning system was put forward, and laid the foundation of implementation of information sharing between mountain torrent disaster non-engineering measures and reservoir project, joint management and collaborative forecasting. A new method was provided to solve complexity problems such as the mountain torrent disaster control of non-engineering measures in daily management and warning information collection of sudden mountain torrent disaster.

\section{Acknowledgements}

This work was financially supported by the National Natural Science Foundation of China (51309164,51579154), Research Projects in Public Interest of Ministry of Water Resources (201301033), the National Key Technology Research and Development Program of the Ministry of Science and Technology of China (2012BAK10B04), the Natural Science Foundation of Jiangsu Province of China (BK20130072), and the Fundamental Research Project of Ministry of Water Resources(Y715015).

\section{References}

[1] JIANG Jinhong, Research on construction of flood detention reservoir for flood control of small mountainous basin[J]. Yangtze River, 2010, 41(14):15-19.

[2] J I Weidong, YUAN Wenbo,WANG Xiaohang,MA Junj ian, et al. Design and application of county-level mountain torrent monitoring and warning decision support system in Hainan province[J]. Hydropower Automation and Dam Monitoring, 2014, 4012

[3] HuJuan,Min Ying,Li Huahong.et al.Meteorological early-warning research of mountain Torrent and Geologic Hazard in Yunnan province[J]. Journal of Catastrophology.2014, 29(1):62-66. 
[4] TAO Yunl,TANG Chuan,DUAN Xu. Landslide and debris flow hazards in Yunnan and their relationship with precipitation characteristics [J].JOURNAL OF NATURAL DISASTERS, 2009, 18(1):180-186.

[5] CONG Weiqing, PAN Mao, LI Tiefeng,REN Qunzhi,LI Renfeng,et al. Quantitative analysis of critical rainfall-triggered debris flows [J].Chinese Journal of Rock Mechanics and Engineering, 2006, 1.

[6] CHEN Guiya,YUAN Yaming,Research on analysis and computation method of critical precipitation amount of torrential flood[J]. Journal of Water Resources Research 2005, 25(4):36-38.

[7] Konstantine P Georgakakos. Analytical results for operational flash flood guidance [J]. Journal of Hydrology, 2006, 317(1):81-103. 